\title{
Performance management in the data-driven oragnisation
}

\author{
Irina Bogdana PUGNA \\ The Bucharest University of Economic Studies, Bucharest, Romania \\ irina.pugna@cig.ase.ro \\ Adriana DUTESCU \\ The Bucharest University of Economic Studies, Bucharest, Romania \\ adriana.dutescu@bsm-mba.ro \\ Georgiana Oana STANILA \\ The Bucharest University of Economic Studies, Bucharest, Romania \\ oana.stanila@cig.ase.ro
}

\begin{abstract}
This paper investigates the challenges raised by the "datafication" of the business environment and its role in reshaping future managerial behavior. These challenges arise specifically from new drivers of performance improvement and strategic development, such as cloud computing, big data, and data analytics. We analyze the factors that significantly change the potential influence that information and information asymmetries ("insight") - resulting from analyzing huge volumes of data - have on organizational competitive advantage. This paper develops a framework to strengthen the value of this insight in an organizational context, and identifies potential areas of future research. The study highlights the conceptual need for, and the role of, analytics as an essential component for deriving the enterprise's value and performance from both structured and unstructured data. It also advocates for repositioning knowledge and human expertise in the new data-driven organizational model. It highlights the need for an increasing role for human skills and judgments ("Big Knowledge") as opposed to a "dictatorship" of data in the new quantified world.
\end{abstract}

Keywords: business analytics, insight, performance management, big data, big knowledge.

\section{Introduction}

We are currently confronted with fundamental changes and challenges in the business environment. New information technologies change the way we perceive management and business models. Cloud computing, Big Data, high-performance computing and powerful analytics are material drivers to performance improvement and strategic development scenarios. Business intelligence and Business Analytics are transforming the paradigms companies are using to define their strategy and to analyze their performance, both for management and integrated financial reporting scope.

To measure and manage their performance, most organizations currently use Performance Management Systems that integrate management methods, techniques, support tools and Business Intelligence components. The main functions of these systems are:

- To gather and store different measures of the business on a regular basis (current state indicators of business performance).

- To gather and store benchmarks and targets (threshold values) and business rules (interpretations of comparison results between current performance indicators and projected values).

- To facilitate roll-ups and drill-downs of analysed indicators alongside with hierarchical aggregation criteria (structured Performance Measurements). 
- To keep the ongoing analysis alert - allowing decision makers to quickly evaluate which business processes are successful, and which need their attention.

Business Performance Information systems were used specially to support decision-making at the strategic level, by balancing various indicators - quantitative and qualitative, lagging and leading - against targeted objectives and industry benchmarks.

The conceptual framework of performance management, conventionally termed Business Performance Management (BPM) was developed in the approach described above (Figure 1).

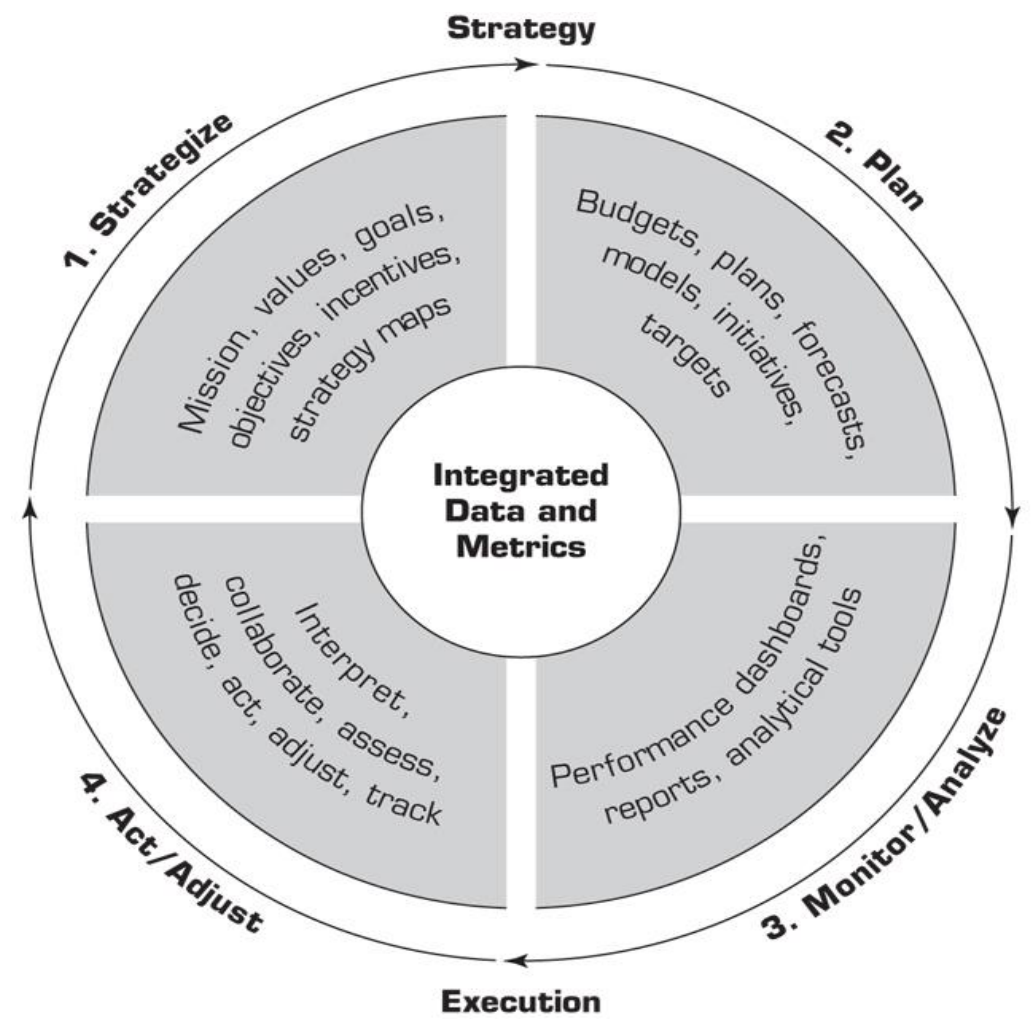

Figure 1. Business Performance Management (BPM)

Source: Sharda et al. (2015).

The main deliverables of Business Performance Information Systems are reports, scorecards and dashboards. While reports offer an in-depth analysis of a specific metric, scorecards are designed for many different verticals of a business, and they track the progress toward goals with the aim of identifying sensitive areas. The latter, originally developed by Kaplan in 1992, are the common instruments nowadays for the highest level of corporate executive staff (Kaplan, 1992). Dashboards, still often described as scorecards, cascade through the organization's hierarchy through tailored metrics and goals that are directly tied to strategy. They are designed to be used by everyone in the organization that has a role requiring the monitoring, management and analysis of business processes.

Table 1. Dashboard types, insight and data

\begin{tabular}{|l|l|l|l|}
\hline & Strategic & Tactical & Operational \\
\hline Insight & What & When and Where & Who and How \\
\hline Data & High-level summary & Mid-level summary & Transactional \\
\hline
\end{tabular}

Source: Adapted from Table 2: Levels of BI, La Grouw, Gail, “Effective Dashboard Design”, p.20,

Electrosmart, Auckland, NZ, 2012. 
As we move into the age of Big Data, analytics is changing the way companies are using sophisticated information technologies to gain insight from their data repositories in order to sustain effective decision making. In the world of big data, virtually every business can be viewed as a big-data problem or initiative.

This new "data-driven" culture is being rapidly adopted by organizations in their attempt to respond to pressures of constantly changing markets and their aspiration to be more socially responsible. They struggle to increase transparency within their operations, to better understand and engage their customers, and to better move towards achieving their strategic vision. One of the most valuable weapons is the "insight" that can be obtained by applying powerful analytics to huge collections of data. It is now the time for firms to engage with the opportunities offered by big data.

This paper investigates the challenges raised by Big Data and Big Analytics for the business environment and that environment's response to this new and relatively unexplored source of value: the value of insight. The study will focus on performance management and business reporting areas.

We aim to answer the following questions:

- What is the impact of Big Data and Big Analytics on the way an organization monitors and analyzes its performance?

- What is the role of the cognitive approach - experience, intuition, judgment - in an increasingly quantified world? Will the aphorism "knowledge is power "be dethroned by the mantra of the modern manager "In God we trust; all the rest: bring data"?

We see this paper as continuing our previous research, which has focused on the impact of information technologies on the approaches organizations take to performance management (Dutescu 2011, Dutescu 2013, Dutescu 2014, Pugna 2013, Pugna 2011, Pugna 2009).

We are also interested in these issues from the educational perspective. As the role of managers - their position, functions and responsibilities - change in the Big Data world, so the education we provide them must also be adapted.

This article starts by reviewing the main aspects of business performance management related with the objectives of this research. The first section provides an overview of the literature and explores the relevance of data-driven organizational model concepts and practice. The research methodology is presented in the second section. The main findings are presented and discussed in the third section. Final remarks, together with the limitations of this study and future research actions are provided in our Conclusions.

\section{Literature review}

Three essentially similar terms are used in the business literature for performance management - Business Performance management (BPM), corporate performance management (CPM), or strategic enterprise management (SEM). The BPM Standards Group (2005), for example, defines BPM as “... a framework for organizing, automating, and analysing business methodologies, metrics, processes, and systems to drive the overall performance of the enterprise. It helps organizations translate a unified set of objectives into plans, monitor execution, and deliver critical insight to improve financial and operational performance" (BPM Standards Group, 2005, p. 2).

Business Performance Management (BPM) ties performance metrics to business strategy using a Business Intelligence (BI) platform for automated data exchange, monitor and analysis. Business Intelligence contributes to the development of methods 
and tools to monitor and manage organizational performance - from the first Executive Information Systems in the 90s, to the more sophisticated Balance Scorecards and Performance Dashboards that we see today. BPM is perceived as being an outgrowth of BI - a framework for information delivery, performance oversight and performance effectiveness. The rise of Big Data brings new challenges for businesses and threat to change the common frameworks used for managing both their activity and performance.

The Big Data phenomenon typically describes "... the incredibly large volume of data that is collected, stored and managed" (Raghupaty, 2014, p. 50). Very big collections of data have existed for decades, as a natural consequence of our constant need to measure, record and analyse the world. The idea of exploiting huge collections of data to obtain useful information and knowledge in a particular context of decision making, has always been the focus of Business Intelligence. The key differences that Big Data brings are the "... emergence of the collection and storage of unstructured data primarily from unconventional sources - social media, blogs, sensors, mobile devices, online chats, etc." (Raghupaty, 2014, p.51) and the velocity with which this data is produced. Although sometimes described as digitization (the process of converting analog data into digital format) of massive quantities of data, Big Data relates to a more complex approach. Schonberger and Cukier (2013) define a new concept for this new process which they term "datafication". In their opinion, "To datafy a phenomenon is to put it in quantified format so it can be tabulated and analysed" (Schonberger and Cukier ,2013, p. 78). The Big Data phenomenon is not simply a quantitative change but, more significantly, a qualitative change.

Powerful data-driven processes that provide insight (Analytics) associated with Big Data are developing rapidly. Analytics are based on data rather than opinion and are quantitative rather than qualitative techniques. "The architectures and platforms, methodologies, and tools have also scaled up in granularity and performance to match the demands of big data." (Ferguson,2012, p. 63).

Business analytics, with its primary goal to "... provide better insight to businesses and organizations, which allows them to achieve a higher level of performance" (Stein and Greenland, 2014, p.30), emerge as the next step in decision management. According to Stein and Greenland, "Analytics should be pervasive within an organization. ... It should be used on an ongoing basis to monitor the performance of the organization and to indicate potential problems" (Stein and Greenland, 2014, p.31). The need for business analytics is constantly growing, as the vast amount of information is forcing companies to use more sophisticated approaches to analyse data and to make better and quicker decisions.

There are some opinions predicting material advantages of integrating Big Data into business performance management, as, for example: a) improving marketing and sales by reaching more insights about customers' preferences, b) better budgets and forecasts and, therefore, more effective decision-making process (Ryan, 2017) c) analytics available for all users at lower costs d) the change of the role, contribution and design of ERP's within company's reporting systems (Marr, 2017).

There is a consistent expectation in the business environment that Big Data may help burst companies' growth, via sales and profits increase (and also cost optimisation), providing also innovation and progress as leading paths.

Decision making based on data and business analytics (the data-driven decisionmaking approach - DDD (Brynjolfsson et al, 2011)), is considered to be the new paradigm in decision management.

This approach, however, is still in its infancy and there are no conventional frameworks for analytics projects or business analytics initiatives. The business 
literature does however highlight the pivotal role of Change Management in Business Analytics (Figure 2). From the management perspective, the main issue lies in understanding the value of insight and convincing an organization to change the way it does business. Business Analytics needs a mind shift more than anything else, as novel analytically based insights identify opportunities to do things differently. "Rather than making decisions based on experience, people need to be convinced to trust data as well as informed recommendations" (Stubbs, 2014, p.7).

PICBE | 820

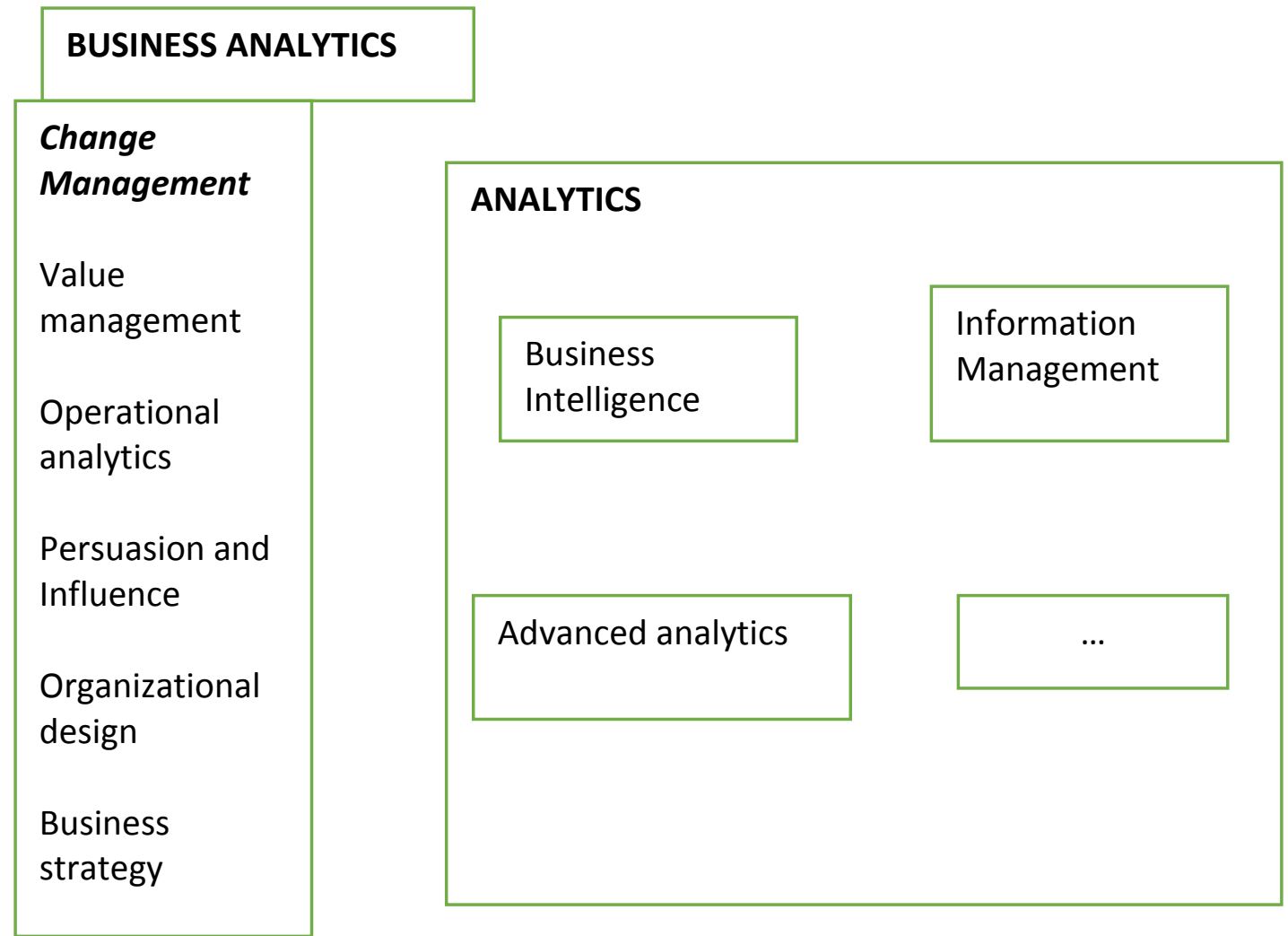

Figure 2. Analytics and Business Analytics

Source: Adapted from Stubbs (2014).

Similarly, IT professionals are developing different types of methodologies, tools and architectures to sustain data-driven decision-making processes. The most cited solutions are:

- Complex Event Processing (CEP) refers to "systems that process or analyse events closer to the creation of those events, prior to storage" (Kudyba, 2014, p. 39).

- Data streaming management systems architecture, in which queries are constantly being generated as data streams from multiple sources - as opposed to the enterprise data warehouse architecture and its query reports based on historical business data. (Anderson and Hardin, 2014).

The data-driven organizational model, although acknowledged by businesses and intensely addressed by IT professionals, is still searching for its place within the BPM framework, as currently understood, or to radically transform it.

\section{Research methodology}

The research method is selected and applied in line with the research objectives. Our research aims to answer the following questions:

- What is the impact of Big Data and Big Analytics on the way an organization monitors and analyzes its performance? 
- What is the role of the cognitive approach - experience, intuition, judgement - in an increasingly quantified world?

The research methodology was based on a qualitative approach, emphasizing a descriptive analysis of the recent relevant research on the subject, complemented by a literature survey in the field.

Literature review and content analysis were the main research methods used, enabling us to collect the material evidence to prepare the answers to the research questions.

Performance management, compared to financial reporting in terms of format and content, relies more on unstructured and qualitative information. This requires a different approach related to data exploring and aggregation. Business Intelligence technologies and applications integrated in the BPM framework currently serve this outcome. However, these technologies are limited in terms of data gathering, representation and analysis, as they require a structured collection of data (the datawarehouse) as source data. Big Data and its analytics can overcome these limits - the new Business Analytics assume to reveal valuable insights from all types of data in real time. Therefore, Business (Big Data) Analytics offer the opportunity of a new and unexplored field, both in terms of research perspectives and business practices.

Our option for a qualitative approach is motivated mainly by the novelty of the subject under research. It is difficult to test empirically the advantages of organizations that implement a fact-driven decision making in the absence of data

In this article, we also use the results of our previous research related to the subject under discussion - the impact of information technologies on performance management.

We also suggest a framework in which Big Data, Big Analytics and data-driven decision components can be integrated in the standard framework of Business Performance Management.

\section{Results and discussions}

Our research focuses on the issues organizations face in their effort to implement a data - driven decision model in the performance management area. It aims to detect the most likely applicable approaches organizations can undertake to effectively manage their performances in an increasingly quantified business environment. Another objective was to grasp the value of knowledge in the new Big Data era.

Our first research question is: What is the impact of Big Data and Big Analytics on the way an organization monitors and analyzes its performance?

The big data era imposes additional requirements on the business performance management process. The decision maker must integrate new variables that impact the conceptual layout of the reports and dashboards, supplementing the volume and the currency of data that must be processed.

Organizations often overreact in addressing this big data challenge, by considering too many variables in the strategic equation. Big data doesn't simply demand more variables, but more meaningful variables. Data sources shouldn't be referenced in the absence of a reason, as data can't provide value outside a conceptual need. This involves the quest to better understand a process with the goal of enhancing its efficiency, productivity or profitability.

Therefore, analysts have to use more intensively data sources that may provide descriptive elements of a given process as new varieties of variables evolve. They must also consider whether a process should be monitored in real-time (velocity, volume) in 
order to uncover strategic insights in the information creation and decision-making process.

The era of big data adds intensity to the analytics as an essential component for deriving value, as it adds new dimensions to the equation.

Different dashboards, less structured than the other types of dashboards, are considered for exploring data. They use information that demands greater context, more extensive history, and subtler performance evaluators; more sophisticated display media and interactions with the data. These new analytical dashboards are mainly used for discovery, and the insight that they provide is an explanation of a certain phenomenon described by transactional data.

Analytical dashboards consider only one aspect of big data complexity - being used mainly for discovery, real time updates are not necessarily needed, although recommended.

The high velocity of streaming data resources demands a real-time dashboard visualization of a given process in order to provide users with a quick view of the impact of variables on Key Performance Indicators. This implies the use of real-time and continuous analytics.

IT professionals are struggling to develop new technologies in order to respond to these issues. Most of these new technologies implement powerful analytics capable of processing massive quantities of streaming data. A variety of mostly unstructured data (text, video, images, financial logs, media and web data) is analysed as soon as it materialises, without being cleaned or transformed according to the rules of a particular storage model. This approach is radically different from traditional BI, where the data collected from different sources is transformed before storage in a specific data mart or in a data warehouse. Big Data Analytics are also particular - they use mainly Artificial Intelligence technologies to discover patterns and to predict the future in the absence of an interpretation process. They are based on correlations and not on causalities. As a consequence, one should just consider the solution that they provide without questioning or trying to understand it. In other words, their user should simply trust the data without questioning it, even when their intuition contradicts it.

All these considerations make the new data-driven decision-making approach quite eccentric for companies. Moreover, the professionals that are needed for Big Data and Big Data Analytics are not easy to find or, if available, extremely expensive. There is a lack of data scientists and curiously, there is no sign that this situation will change, as there are currently few university programs offering a relevant qualification (Chen and Chiang,2012). In addition to technical competence, data scientists also need to be sufficiently familiar with the specific features of their organisations, in order to deliver maximum value to the executive.

As a consequence, most companies, although acknowledging the need to implement a data-driven organizational model, are still waiting for a more feasible and more widely accepted solution, and a more favourable human resource context. They are currently left Data Rich but Insight Poor.

Big Data and the value of the insight it can provide, however, can't be ignored. In our opinion, Big Data shouldn't be treated separately from the more traditional form of analytics. We propose a gradual approach rather than a more radical one, in which different data-driven performance management components are integrated in the classical BPM framework.

One possible approach is to integrate complex event processing (CEP) within traditional analytics, where data is stored before it is analysed. This type of analytics is 
done as a front end to historical analysis in order to aggregate raw data before storing it for further analysis. This combination of complex event processing and front-ending historical analysis can be a very influential, multistage approach to the analysis of data and hence acting on intelligence sooner than is otherwise possible.

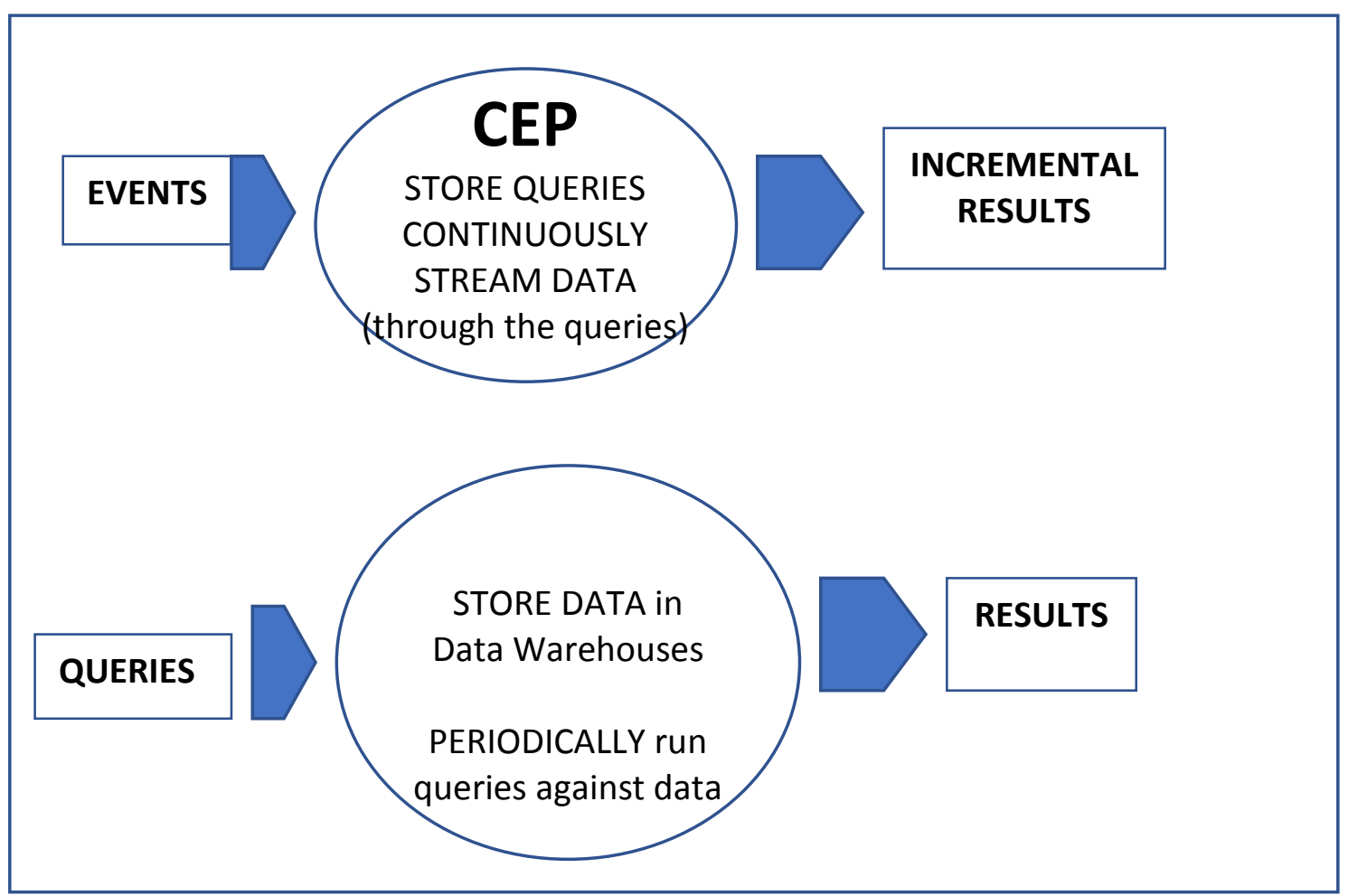

Figure 3. Complex Event Processing and front-ending historical analysis

Source: Adapted from Figure 2.13 Hybrid multistage analytics, Kudyba, S. "Information creation through analytics", Big Data, Mining and Analytics, Taylor and Francis Group, USA, 2014

We are proposing a general framework for performance management that is developed on the basis of the existing BPM architecture (BPM Standards Group 2005). This framework integrates modules for Big Data real-time and continuous analysis into a hybrid capability within the organization. (Figure 4). Our intention is to further refine this model in order to explore its viability in a range of business contexts, in our future research. 
REPORT AND QUERY TOOLS, SCORECARDS, DASHBOARDS, COLLABORATION

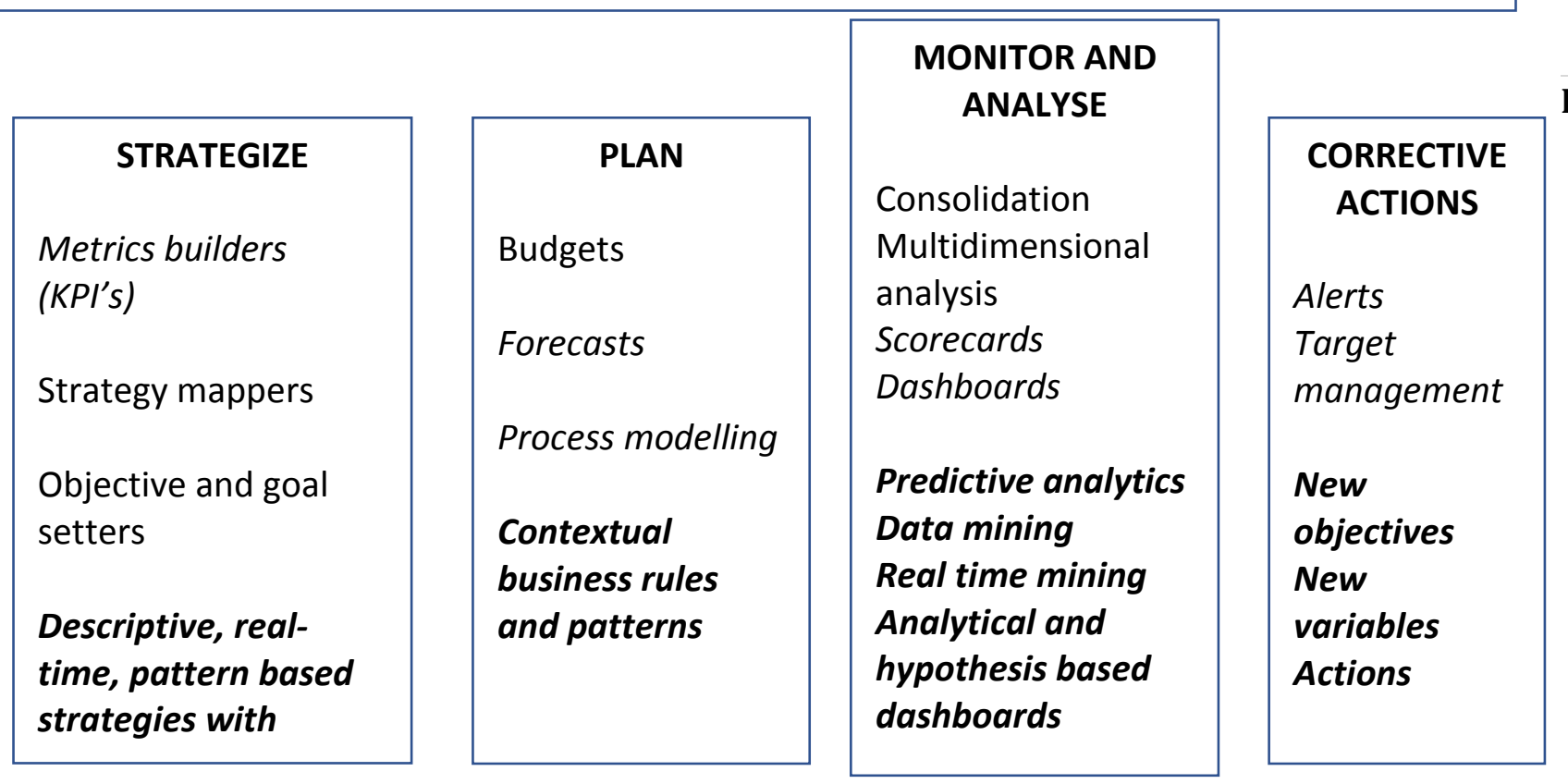

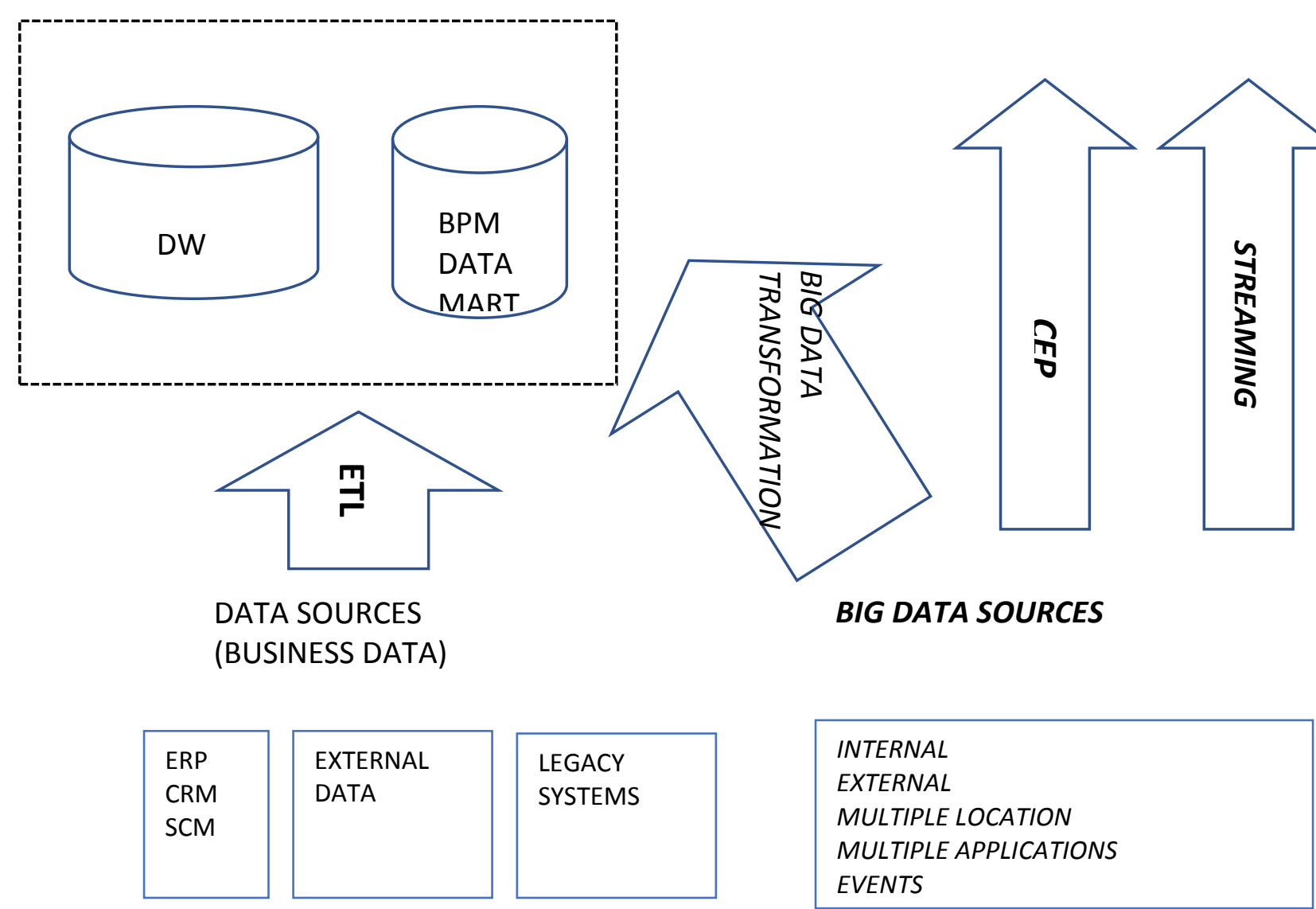

Figure 4. Integrated architecture for performance management

Source: Author's own research - an extension covering Big Data Sources, Analytics and Insight of BPM standard framework (2005).

In the figure above we use the following abbreviations: 


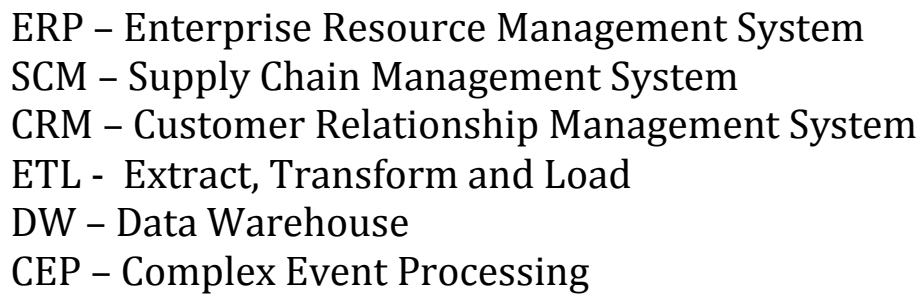

In this framework, we suggest a unified data architecture (business data extracted from different information systems and big data). This unified data can be further explored by traditional (Business Intelligence Analytics) and Big Data Analytics.

In the figure above, the novel components are highlighted in bold italics, while the current ones (that will be however influenced by the new approach) are highlighted in italics. For example, in defining the performance metrics, the user will have access to new types of insight revealed by previously unexplored data.

Our second research question is: What is the role of the cognitive approach experience, intuition, judgement - in an increasingly quantified world?

In the world of Big Data, the role of human judgment, intuition and expertise is repositioned. Analytics are more quantitative than qualitative and are based on data rather than on opinion. Thus, business analysts must rely on the results they provide, without questioning them. The application of analytics has proven to be superior to decision making that relies solely on the intuition and experience of executives. However, if the meaning of the results of the analytics can't be delivered in a coherent way, then the value of those results will be difficult to assess.

The use of performance and executive dashboards for visualising KPIs has, undoubtedly, a clarifying role. Nevertheless, the business analyst must have a comprehensive understanding of the organization in order to communicate effectively to the management.

We are supporters of data decision making, but we strongly believe that intuition-based decision making should also be applied to understand and interpret the results. The concept of "knowledge" shouldn't be dethroned in the Big Data era, but needs to be reinforced as "Big Knowledge", as its role increases with the complexity of our world. We need knowledge to make sense of the solutions provided by analytics, to address the right data, and also to define the conceptual need for the analytics themselves.

One threat in a Big Data world is that we may be tempted to apply analytics to all available data, and this can lead to misleading answers. Using the right data in a particular context is crucial for obtaining a valuable insight but, when faced with larger and larger quantities of data, its identification becomes increasingly difficult.

Above all, today's managers need to know what to ask, and not necessarily how to solve their problems - that is the role of analytics! They also need to be flexible enough to trust data and to take full advantage of the insight it provides.

However, they should question the sense underlying the mantra of the modern manager: "In God we trust; all the rest: bring data" and be aware of both the limits of data (Garbage In, Garbage Out) and the danger of a "dictatorship of data".

\section{Conclusions}

This article has attempted to explore challenges raised by the "datafication" of the business environment and its role in reshaping future managerial behavior. We focused 
our research on the performance management area, as it is a crucial area for business sustainability, as well as for education (Ghinea et al., 2017) .

In order to respond to the main research objectives, we conducted an analysis of the recent relevant research on the subject, complemented by a literature survey in the field.

We have discussed the impacts of Big Data and its analytics on current performance management practices and we have advocated for the implementation of the new Business Analytics throughout the process. We have examined different approaches an organization can envisage in order to make sense of all the available data.

The main contribution of this study is a proposal for a general framework for Business Performance Management. This integrates modules for Big Data real-time and continuous analysis into a hybrid capability, in order to make sense of all the available data inside and outside the organization. This framework completes the existing BPM framework and can be considered as being a stage in the process of implementing a data-driven decision-based performance management approach.

Another result of the research concerns the role of human intuition, experience and judgment in the new data-driven decision-making paradigm. It is generally considered that the role of knowledge is weakened in a Big Data world, and that data and correlations between them - offer insights that are correct and should not be questioned. In contrast, we advocate for an increasing role for knowledge. We support this position with arguments related to the new role of knowledge (as Big Knowledge) in an increasingly quantified world.

However, all the underlying themes discussed in this article have broader implications for decision-making models. Each of these themes can be explored further and more deeply. The Big Data era will radically transform these models and, consequently, the set of skills and attitudes related to managerial behaviour.

The main limitation of this research derives from a current lack of data related to managers' attitudes, approaches and thoughts on the subject and, indeed, the current lack of penetration of datafication within businesses. In future work, we aim to undertake qualitative research - examining the impact of datafication within organizations and the viability of our proposals directly - as and when conditions within the business community adjust to and take up these new approaches and technologies.

Nevertheless, we have met our current objectives. We have explored some of the general issues organizations face with respect to data-driven decision model and we identified a general framework for BPM that integrates Business Analytics elements.

As a further research objective, we envisage to refine the proposed framework in order to explore its viability in a range of business contexts.

\section{References}

Albescu, F. \& Pugna, I. \& Paraschiv, D. (2007). Business Information Engineering - an approach in integrating Business \& Information Technologies, available at http://cig.ase.ro/revista_coig/ContinutNumar.aspx

Anderson,B, \& Hardin, M. (2014) Streaming data in the age of Big Data, in (Kudyba, S. (2014)), 165-179

Barber, S. (2014) Using CEP for real-time Data Mining, in (Kudyba, S. (2014)), 179-210. Boldeanu, D. \& Pugna, I. (2014). The analysis of the influence factors affecting the performance of pharmaceutical companies, available at http://www.ectap.ro/theoretical-and-applied-economics 
BPM Standards Group (2005). Business Performance Management : Industry Framework Document, available at http://www.bpmstandardsgroup.org

Brown, M., (2014), Transforming unstructured data into useful information, in (Kudyba, S. (2014)), 211-231

Brynjolfsson. E. \& Hitt, L. \& Kim, H. (2011). Strength in numbers : How does data driven decision making affect firm performance, available at SSRN:http://papers.ssm.com/sol3/papers.cfm?abstract_id-1819486

Chen, H \& Chiang, R., and Storey, V. (2012). Business Intelligence and Analytics: From Big Data to Big Impact, MIS Quarterly vol.36, No. 4, 1165-1118

Dutescu A, Popa A.F., Ponoraca A.G. (2014) Sustainability of the turism industry, based on financial key performance indicators , Amfiteatrul Economic, vol. 16, special no. 8, pag. 1048-10, 2014, ISSN 1582-1062

Dutescu A, Popa A.F., Ponoraca A.G., Stanila G.O.(2013),Effcets of mergers and acquisitions on the financial performance of the target company, Challenges of the Knowledge Society, vol 7, edition 7th, pg. 1041-1050, ISSN 2068-7796

Dutescu A, Popa A.F., Stanila G.O, Sahlian D.N., Trasca D.L. .(2011)- Performance management- a new concept in the oro-dental health system, article presented at the AMEO Confference, pg. 186-192, ISSN 2234-7634

Ferguson, M. (2012). Architecting a big data platform for analytics, Intelligent Business Strategies, Business Release, N

Ghinea, V. M., Dima, A. M., \& Hadad, S. (2017). EXCELLENCE MODEL FOR SUSTAINABLE CONVERGENCE IN THE EU HIGHER EDUCATION. Amfiteatru Economic, 19(11), 1107-1122.

Kaplan. R \& Norton. D (1992).The Balanced Scorecard-Measures that drive performance, Harvard Buisness Review, January-february 1002, 71-79

Kudyba, S. \&Kwatintez,M. (2014). Introduction to the Big Data Era, in (Kudyba, S. (2014)), 1-16.

Kudyba, S. (2014). Information Creation Through Analytics, in (Kudyba, S. (2014)), 1749.

Kudyba, S. (2014). Big Data, Mining and Analytics - Components of strategic decision making, CRC Press, Taylor and Francis Group, USA

Maar. B (2017) available at http://kpilibrary.com/topics/3-ways-big-data-analyticswill-change-enterprise-performance-management;

Yurgosky, P. (2014). Executive/Performance Dashboards, in (Liebowitz, J. 2014)), 55-92

La Grouw, G. (2012) “Effective Dashboard Design”, Electrosmart, Auckland, NZ

Liebowitz, J. (2014) Business Analytics - An Introduction, CRC Press, Taylor and Francis Group, USA

Pugna, I.\& Boldeanu, D. (2013). Management and Business Intelligence initiatives in a collaborative intelligence framework, AMIS, ISSN 2247-6245, P. 444-459

Pugna, I.\& Albescu, F. \& Sova, R (2011). Beyond reporting in Business Intelligence Intelligence through Analytics, AMIS, ISSN 2247-6245

Pugna, I. \& Albescu, F. \& Babeanu, D. (2009). The role of business intelligence in business performance management, available at

http://anale.steconomiceuoradea.ro/2010/04/18-tom-2009-volumul-ivmanagement-marketing/

Raghupathi, W.\& Raghupaty, V. (2014). Big Data Analytics - Architectures Implementation, Methodology, and Tools, in (Kudyba, S. (2014)), 49-70. 
Ryan. N (2017), available at http://www.accaglobal.com/ca/en/student/examsupport-resources/professional-exams-study-resources/p5/technicalarticles/big-data-pm.html)

Savas, O. \& Nguyen T.T. \& Deng, J. (2014). Big Data Analytics for Business Intelligence, in (Liebowitz, J. (2014)), 119-148.

Schonberger, V. \& Cukier, K. (2013) Big Data - A revolution that will transform how we live, work and think, John Murray Publishers, UK

PICBE | 828

Stein, F. \& Greenland, A. (2014). Producing Insight from Information through Analytics, in (Liebowitz, J (2014)), 29-55.

Stubbs, E. (2014). The Value of business analytics, p. in (Liebowitz, J (2014)), 1-28.

Turban, E. \& Sharda, R. \& Delen, D. (2015). Business Intelligence and Analytics, $10^{\text {th }}$ Edition, Pearson Education, 2015 